\title{
Modified endoscopic mucosal resection techniques for treating precancerous colorectal lesions
}

\author{
Georgios Tziatziosa, Paraskevas Gkolfakis ${ }^{b}$, Vasilios Papadopoulosc, loannis S. Papanikolaoua, \\ Lorenzo Fucciod, Antonio Facciorusso', Alanna Ebigbo', Stefan Karl Gölder', Andreas Probst', \\ Helmut Messmannf, Konstantinos Triantafyllou ${ }^{a}$
}

Medical School, National and Kapodistrian University of Athens, "Attikon” University General Hospital, Athens, Greece; Erasme University Hospital, Université Libre de Bruxelles, Brussels, Belgium; Koutlimbaneio \& Triantafylleio General Hospital, Larissa, Greece; S. Orsola-Malpighi Hospital, University of Bologna, Bologna, Italy; University of Foggia, Italy; University Hospital Augsburg, Augsburg, Germany

\section{Abstract}

Endoscopic mucosal resection (EMR) is a technique allowing efficacious and minimally invasive resection of precancerous lesions across the entire gastrointestinal tract. However, conventional EMR, involving injection of fluid into the submucosal space, is imperfect, given the high rate of recurrence of post-endoscopic resection adenoma, especially after piecemeal resection. In light of these observations, modifications of the technique have been proposed to overcome the weakness of conventional EMR. Some of them were designed to maximize the chance of en bloc resection-cap-assisted EMR, underwater EMR, tip-in EMR, precutting, assisted by ligation device-while others were designed to minimize the complications (cold EMR). In this review, we present their modes of action and summarize the evidence regarding their efficacy and safety.

Keywords Endoscopic mucosal resection, colorectal polyps, underwater, cold, cap

Ann Gastroenterol 2021; 34 (1): 1-16
${ }^{\text {a}}$ Hepatogastroenterology Unit, Second Department of Internal Medicine-Propaedeutic, Medical School, National and Kapodistrian University of Athens, "Attikon" University General Hospital, Athens, Greece (Georgios Tziatzios, Ioannis S. Papanikolaou, Konstantinos Triantafyllou); ${ }^{b}$ Department of Gastroenterology Hepatopancreatology and Digestive Oncology, Erasme University Hospital, Université Libre de Bruxelles, Brussels, Belgium (Paraskevas Gkolfakis); 'Department of Gastroenterology, Koutlimbaneio \& Triantafylleio General Hospital, Larissa, Greece (Vasilios Papadopoulos); ${ }^{\mathrm{d} G a s t r o e n t e r o l o g y ~ U n i t, ~ D e p a r t m e n t ~}$ of Medical and Surgical Sciences, S. Orsola-Malpighi Hospital, University of Bologna, Bologna, Italy (Lorenzo Fuccio);

${ }^{\mathrm{e}}$ Gastroenterology Unit, Department of Surgical and Medical Sciences, University of Foggia, Italy (Antonio Facciorusso); fDepartment of Gastroenterology, University Hospital Augsburg, Augsburg, Germany (Alanna Ebigbo, Stefan Karl Gölder, Andreas Probst, Helmut Messmann)

\section{Conflict of Interest: None}

Correspondence to: Ioannis S. Papanikolaou, MD, $\mathrm{PhD}$, Associate Professor of Gastroenterology and Internal Medicine. Hepatogastroenterology Unit, Second Department of Internal Medicine - Propaedeutic, Medical School, National and Kapodistrian University of Athens, "Attikon" University General Hospital, 1, Rimini Street, 12462 Athens, Greece, e-mail: ispapn@hotmail.com

Received 19 March 2021; accepted 24 April 2021; published online 2 July 2021

DOI: https://doi.org/10.20524/aog.2021.0647

\section{Introduction}

Colonoscopy with removal of adenomas reduces the incidence and mortality of colorectal cancer [1]. The vast majority of colorectal adenomas are diminutive $(\leq 5 \mathrm{~mm})$, posing no technical difficulty during removal [2]. Nonetheless, resection of larger $(\geq 2 \mathrm{~cm})$ adenomas, or those situated in difficult positions, e.g., between haustral folds, close to the dentate line or the ileocecal valve, can be challenging [3]. Endoscopic mucosal resection (EMR) is advocated as the firstline modality for removing large, flat or laterally spreading colorectal polyps [4]. Typically, the procedure starts with submucosal injection of a fluid underneath the lesion, aiming to create a submucosal cushion separating the lesion from the muscularis propria. This submucosal space expansion facilitates snaring of flat or sessile lesions, reduces the risk of transmural thermal injury and perforation, while it also indicates lesions where deeply invading neoplastic tissue is already present, preventing tissue lifting (the so-called "non-lifting sign") [5]. Still, it remains imperfect; the complete resection rate diminishes as polyp size increases, ranging from $2-30 \%$ when polyp size is greater than $10 \mathrm{~mm}$ [6], while more ominous is the high rate of recurrence of post-endoscopic resection adenoma, which may reach as high as $20 \%$, especially with piecemeal EMR [7,8]. Moreover, submucosal injection can lead to 
significant operational difficulties, augmentation of lesion size and bleeding at the site of needle puncture $[9,10]$. On the other hand, evidence underlines that the procedure can be performed even without submucosal injection $[11,12]$. Aiming to address the aforementioned limitations and improve the procedure's outcomes, several modifications of the technique have been proposed [13]. This manuscript reviews the current literature, highlighting variations and modified EMR techniques used for colorectal lesions removal.

\section{Materials and methods}

We conducted a comprehensive review of the English literature published in the PubMed electronic database until October 2020. We used the following key words during our search: "endoscopic mucosal resection", "colorectal polyps", "underwater", "cold", "cap", "tip", band", and "outcome". All types of trials published in the English language were considered eligible for inclusion, while non-human, ex-vivo or pilot studies, editorials, narrative reviews, case reports/series, and video cases were excluded. For the purposes of this review, we present the evidence in a top-down approach, focusing mainly on the highest level, namely randomized controlled trials (RCTs) and metaanalyses, whenever possible. In the absence of the aforementioned categories of evidence, some of the strongest data available from other types of studies (i.e., cohort, cross-sectional, etc.) are discussed to underline the context of each technique.

\section{Underwater EMR (U-EMR)}

\section{The technique}

In U-EMR the lumen is filled with water, totally immersing the polyp without any fluid injection to the submucosal space, and resection follows using electrocautery current [14]. The initial observations that prompted the development of U-EMR arose during endosonography; there, it was noticed that water submersion preserves the circular shape of colonic muscularis propria, while the adenoma-bearing mucosa and submucosa layer may float away from the muscularis propria (Table 1) [5]. The presence of water also allows safe entrapment of the lesion within the snare, leaving out the muscularis layer, reducing the possibility of an immediate perforation (Fig. 1).

\section{The evidence}

\section{Data from prospective and cohort studies}

The first study to evaluate the efficacy and safety of this novel method was published in 2012 by Binmoeller et al [15]. The authors performed U-EMR for 62 colorectal lesions ( $>2 \mathrm{~cm}$ in size, mean size $34 \mathrm{~mm}$ ) achieving $100 \%$ therapeutic efficacy and an excellent safety profile. These results were confirmed in subsequent prospective series and cohort studies [11,16-18]. Interestingly, in the study by Curcio et al [19], endoscopists with no previous specific dedicated training in U-EMR, achieved a $100 \%$ complete resection rate, signifying the method's "operator-friendly" character. So far, 6 RTCs have compared U-EMR and conventional EMR (C-EMR) in terms of polypectomy outcomes (i.e., en bloc and complete resection, adverse events rate and procedure time; Table 2) [20-25]. A large international study, recruiting 303 patients with 303 large $(\geq 15 \mathrm{~mm})$ colonic polyps, showed a significant benefit for U-EMR compared to C-EMR regarding curative resection, defined as presence of residual neoplasia on 3-6-month surveillance colonoscopy ( $8.5 \%$ vs. $16.8 \%, \mathrm{P}=0.05$ ). Moreover, a significantly higher rate of en bloc resection (48.1\% vs. $24.1 \%, \mathrm{P}<0.01)$ and a shorter resection total procedure time (10.8 vs. $13.2 \mathrm{~min}, \mathrm{P}=0.01$ ) were achieved by U-EMR [20]. Similar results were reported from a multicenter Japanese RCT [21]. The authors randomized patients with intermediatesized (10-20 mm) sessile colorectal polyps to undergo either U-EMR or C-EMR, with R0 resection rate being the primary endpoint. Their analysis showed a significantly higher R0 resection rate when U-EMR was used: 69\% (95\%confidence interval [CI] 59-77\%) vs. 50\% (95\%CI 40-60\%), P=0.011. En bloc resection rate was also significantly higher: $89 \%$ (95\%CI $81-94 \%)$ vs. $75 \%$ (95\%CI 65-83\%), $\mathrm{P}=0.007$. Two more RCTs from Europe were published as abstracts [22,23]. The first [22] randomized 58 and 59 patients with large sessile or flat colonic lesions to U-EMR or C-EMR, respectively. Preliminary results of this study showed similar en bloc resection rates $(27.6 \%$ for U-EMR vs. $18.6 \%$ for $C$-EMR, $\mathrm{P}=0.27$ ) and adverse events rates (15.5\% for $\mathrm{U}-\mathrm{EMR}$ vs. $16.9 \% \mathrm{C}-\mathrm{EMR}, \mathrm{P}=0.1$ ). The second [23], a multicenter study, randomized 267 consecutive lesions (mean size $32.75 \mathrm{~mm}$ ) to either U-EMR ( $\mathrm{n}=126$ including 15 recurrences) or C-EMR ( $\mathrm{n}=141,16$ recurrences). U-EMR was beneficial in terms of complete ( $90 \%$ vs. $82 \%$; $\mathrm{P}=0.04$ ), but not en bloc ( $25 \%$ vs. $20 \%$; $\mathrm{P}=0.56)$ resection rate. At 3-6 months, recurrence was higher in the C-EMR group, but the difference did not reach significance. In the largest RCT [24], incomplete resection rates did not differ between the 2 groups ( $2 \%$ vs. $1.9 \%$, respectively, for U-EMR and C-EMR; $\mathrm{P}=0.91$ ). Notably, no polypectomy-associated adverse events were reported in either group. In a multicenter RCT analyzing small colorectal polyps (4-9 mm) [25], both complete $(83.1 \%$, 95\%CI 75.690.6\% vs. $87.3 \%$, 95\%CI 80.7-94.0\%; $\mathrm{P}=0.478$ for U-EMR and C-EMR, respectively) and en bloc resection rate (94.4\%, 95\%CI 89.8-99.0\% vs. $91.5 \%, 95 \%$ CI 86.0-97.1\%; $\mathrm{P}=0.512$ for $\mathrm{U}-\mathrm{EMR}$ and C-EMR, respectively) were similar between the 2 groups. Considered overall, these prospective studies suggest that U-EMR may offer better complete resection rates compared with C-EMR, while reducing the risk of recurrences, but there are no definitive data on the en bloc resection rates. In any case, en bloc resection rate is closely related to polyp size [4]. For lesions $<10 \mathrm{~mm}$, the data suggest that neither of the 2 methods appears superior. However, the respective percentage with C-EMR for intermediate-sized $(10-20 \mathrm{~mm})$ or intermediateto-large $(20-30 \mathrm{~mm})$ lesions drops significantly. This may be a result of suboptimal injection technique: the lesion may 
Table 1 Main characteristics of modified EMR techniques

\begin{tabular}{|c|c|c|c|}
\hline Technique & Basic principle & Advantages & Disadvantages \\
\hline $\begin{array}{l}\text { Underwater } \\
\text { EMR }\end{array}$ & $\begin{array}{l}\text { Water immersion preserves circular shape of colonic muscularis } \\
\text { propria and separates mucosa and submucosa from the } \\
\text { muscularis mucosae, allowing snare entrapment of the lesion } \\
\text { while protecting against perforation and transmural thermal } \\
\text { injury }\end{array}$ & $\begin{array}{l}\text { High en bloc resection rate } \\
\text { Low recurrence rate } \\
\text { Low complication rate } \\
\text { Reduced procedure time } \\
\text { Easy to learn and perform } \\
\text { No additional equipment } \\
\text { needed; low cost } \\
\text { High quality data support } \\
\text { its use }\end{array}$ & $\begin{array}{l}\text { Limited visibility due to } \\
\text { intestinal peristalsis and } \\
\text { poor bowel preparation }\end{array}$ \\
\hline Cold EMR & $\begin{array}{l}\text { After submucosal injection, the lesion is elevated with a margin } \\
\text { of surrounding normal mucosa; resection is commenced at one } \\
\text { side of the lesion margin, including a margin }(3-4 \mathrm{~mm}) \text { of normal } \\
\text { tissue. The diameter of each tissue fragment should be limited to } \\
<10 \mathrm{~mm} \text { for each resection }\end{array}$ & $\begin{array}{l}\text { Less clinically significant } \\
\text { bleeding } \\
\text { Lower cost } \\
\text { No deep mural injury } \\
\text { Resection at polyp } \\
\text { detection; no return for } \\
\text { EMR } \\
\text { No prophylactic clip } \\
\text { Easier assessment of the scar } \\
\text { Advantageous in resection } \\
\text { of sessile serrated polyps }\end{array}$ & $\begin{array}{l}\text { No advantage of ablation } \\
\text { in reducing residual tissue } \\
\text { Greater number of } \\
\text { resected fragments } \\
\text { Piecemeal resection } \\
\text { of polyps } 10-20 \mathrm{~mm} \\
\text { increases surveillance } \\
\text { burden } \\
\text { Need for dedicated snare } \\
\text { Limited data for } \\
\text { efficacy in conventional } \\
\text { adenomas resection }\end{array}$ \\
\hline $\begin{array}{l}\text { Cap-assisted } \\
\text { EMR }\end{array}$ & $\begin{array}{l}\text { Using a transparent plastic cap mounted on the tip of the } \\
\text { endoscope, after submucosal injection and elevation, the lesion } \\
\text { is snared and drawn inside the cap using suction. Application of } \\
\text { electrocautery finally resects the lesion }\end{array}$ & $\begin{array}{l}\text { Facilitates operative field } \\
\text { visualization } \\
\text { Beneficial for lesions } \\
\text { located in difficult sites, } \\
\text { e.g.,, ileocecal valve } \\
\text { Suction of normal } \\
\text { mucosa lowers recurrence } \\
\text { possibility } \\
\text { Suction and insufflation of } \\
\text { air unaffected }\end{array}$ & $\begin{array}{l}\text { Increased perforation risk } \\
\text { Need for large } \\
\text { submucosal injection } \\
\text { volume that may interfere } \\
\text { with view } \\
\text { Limited data for its use }\end{array}$ \\
\hline Tip in EMR & $\begin{array}{l}\text { After submucosal injection, a mucosal incision using the tip of } \\
\text { the snare is made on the oral side of the lesion; the tip of the } \\
\text { snare is anchored into the mucosal incision site and the lesion is } \\
\text { grasped, while the tip of the snare remains anchored }\end{array}$ & $\begin{array}{l}\text { High en bloc resection rate } \\
\text { Reduced procedure time } \\
\text { Easy to learn }\end{array}$ & Limited data for its use \\
\hline $\begin{array}{l}\text { EMR } \\
\text { precutting }\end{array}$ & $\begin{array}{l}\text { Following the submucosal injection, a circumferential incision is } \\
\text { performed with an ESD knife. Next, a snare is used to capture the } \\
\text { lesion at the mucosal circumferential incision site and removes } \\
\text { the polyp }\end{array}$ & $\begin{array}{l}\text { High technical success rate } \\
\text { High en bloc resection rate } \\
\text { Low recurrence rate }\end{array}$ & $\begin{array}{l}\text { Increased complication } \\
\text { risk } \\
\text { Technically demanding } \\
\text { procedure } \\
\text { Higher cost } \\
\text { For experienced } \\
\text { endoscopists }\end{array}$ \\
\hline $\begin{array}{l}\text { EMR with } \\
\text { ligation } \\
\text { device }\end{array}$ & $\begin{array}{l}\text { A multi-band ligation device is used on the tip of a colonoscope. } \\
\text { Submucosal solution is performed, while the lesion is aspirated } \\
\text { into the ligation device. After deployment of an elastic band } \\
\text { the lesion is captured within the snare and then resection is } \\
\text { performed below the band }\end{array}$ & $\begin{array}{l}\text { Useful for small rectal } \\
\text { neuroendocrine tumors } \\
\text { Equal complete resection } \\
\text { rate to ESD for rectal NETs } \\
\text { Shorter procedural duration } \\
\text { Shorter hospital admission }\end{array}$ & $\begin{array}{l}\text { No data for its use in } \\
\text { other colorectal lesions } \\
\text { Additional cost }\end{array}$ \\
\hline
\end{tabular}

EMR, endoscopic mucosal resection; ESD, endoscopic submucosal dissection; NET, neuroendocrine tumor

be difficult to grasp when the fluid has not been applied homogenously underneath, while excessive fluid injection or bleeding by the needle may lead to lesion concealment. Contrariwise, U-EMR can indeed be advantageous for polyps $\geq 20 \mathrm{~mm}$, or even larger, as the water-induced contraction of mucosa and submucosa layers may prevent already large lesions from extending further, allowing them eventually to be captured by normally sized snares [15].

\section{Data from meta-analyses}

Three meta-analyses pooled data regarding the efficacy and safety of U-EMR as a standalone procedure [12,26,27] (Table 2). Although their primary outcomes differed, they shared common conclusions. Spadaccini et al investigated outcomes from 508 lesions removed with U-EMR [12]. The pooled rate of complete resection was $96.36 \%$ (95\%CI 91.77-98.44\%), with 


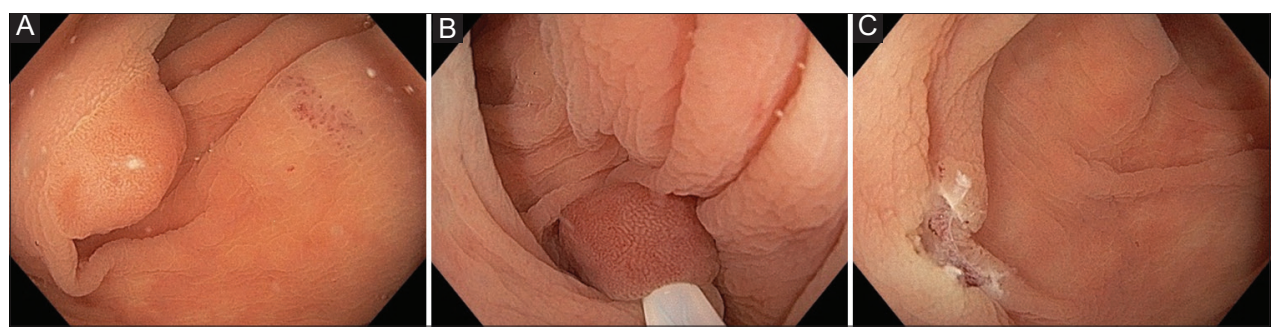

Figure 1 Example of a polyp resected by underwater endoscopic mucosal resection. (A) after air has been removed, the lumen is filled with water causing the polyp to float; (B) the polyp is captured en bloc within a snare; (C) final defect following en bloc underwater resection (Photos are from author's personal archive)

en bloc resection of $57.07 \%$ (95\%CI 43.2-69.9\%). Similarly, in another meta-analysis [26], the pooled en bloc resection rate was 59\% (95\%CI 43-75\%; $\mathrm{P}<0.01$ ), while the pooled rates for recurrence/residual adenoma and delayed bleeding were $5 \%$ (95\%CI $2-8 \%$ and $2 \%, 95 \%$ CI $1-3 \%$ ), respectively. The high degree of heterogeneity encountered $\left(I^{2}=97 \%\right)$, calls for careful interpretation of these results. Finally, one recent meta-analysis evaluated the rate of adverse events and residual polyps, stratified by polyp size (10-19 $\mathrm{mm}$ and $\geq 20 \mathrm{~mm}$ ) [27]. Pooled data for a total of 1142 polyps showed that adverse event and residual polyp rates were not significantly lower when U-EMR was applied for polyps of $10-19 \mathrm{~mm}$ (3.5\% vs. $4.3 \%$ and $1.2 \%$ vs. $2.6 \%$, respectively). The meta-regression analysis identified polyp size as an independent predictor for both complete $(\mathrm{P}=0.03)$ and en bloc resection $(\mathrm{P}=0.01)$.

Several meta-analyses compared U-EMR with conventional EMR (Table 2). A pooled analysis showed that U-EMR achieves higher en bloc resection rate (odds ratio [OR] 1.61, 95\%CI 1.02-2.53; $\mathrm{P}=0.04)$ and lower rate of recurrence/ residual adenoma (OR 0.18, 95\%CI 0.07-0.46; $\mathrm{P}<0.01$ ) [26]. Subsequently, 4 updated meta-analyses were published [28-31]. Kamal et al [28], demonstrated a significant benefit of U-EMR in terms of en bloc resection (risk ratio [RR] 1.16, 95\%CI 1.08-1.26; $\mathrm{P}<0.001$, complete resection rate confirmed by histology (RR 0.75, 95\%CI 0.57-0.98; $\mathrm{P}=0.03$ ), as well as local recurrence (RR 0.26, 95\%CI 0.12-0.56; $\mathrm{P}<0.001$ ). Choi et al assessed the outcomes from 614 polyps resected by U-EMR and 623 by C-EMR [29]. U-EMR resulted in higher rates of en bloc resection rate (OR 1.84, 95\%CI 1.42-2.39; $\mathrm{P}<0.001$ ). In another meta-analysis [30], U-EMR was associated with higher en bloc resection rate (85.87\% vs. $73.89 \%$; RR 1.14 , 95\%CI 1.01-1.30; $\mathrm{P}<0.05)$. Finally, in the most recent one [31], $\mathrm{U}$-EMR was associated with a significantly lower rate of incomplete resection (OR 0.19, 95\%CI 0.05-0.78; $\mathrm{P}=0.02$ ) and recurrence (OR 0.41, 95\%CI 0.24-0.72; $\mathrm{P}=0.002$ ) compared to C-EMR. Moreover, the rates of both overall complications and intraprocedural bleeding were significantly lower with U-EMR (RR 0.66, 95\%CI 0.48-0.90; $\mathrm{P}=0.008$, and RR 0.59, $95 \%$ CI $0.41-0.84 ; \mathrm{P}=0.004$, respectively), underlining the safety of the procedure. Considered overall, these meta-analyses add new insights to the previously reported RCTs, suggesting that U-EMR achieves significantly higher en bloc resection rates and also confirming the lower recurrence rate associated with the technique compared to C-EMR.

\section{Cold EMR}

\section{The technique}

Electrical energy is pivotal for the efficacy and safety of polypectomy, allowing wider and deeper resection, reducing the possibility of residual neoplasia and expediting hemostasis [5]. On the other hand, the greater volume and depth of resected tissue may lead to thermal injury of the colonic wall and a higher risk of perforation [5]. Cold EMR is a hybrid technique (Table 1); submucosal injection and elevation of the lesion remain unaltered, but the resection is performed without the use of electrocautery (Fig. 2) [32]. However, the superiority of this procedure seems to diminish as the size of the polyp increases, suggesting a size-dependent efficacy $[33,34]$.

\section{The evidence}

Data regarding the efficacy of cold EMR are limited, heterogeneous and of questionable quality (Table 3). Cold EMR performs well for non-pedunculated polyps sized 6-10 mm, achieving comparable rates of histological complete resection to C-EMR (92.8\% vs. 96.37\%) [35]. These results were corroborated by an RCT, where colorectal polyps 6-20 mm in size were randomly assigned to cold or C-EMR [36]. No differences in the core procedural outcomes were reported for cold EMR compared to C-EMR. Similarly, en bloc and histological complete resection by cold EMR were promising (cold EMR 82.5\% vs. C-EMR 63.8\%) [37]. Nonetheless, robust data assessing the performance in resection of larger polyps ( $\geq 20 \mathrm{~mm}$ ) remain limited. In their study, Piraka et al [38] showed a residual or recurrent adenoma rate of $9.7 \%$, with median polyp size being significantly larger in those with residual/recurrent adenoma ( 37.1 vs. $19.1 \mathrm{~mm}, \mathrm{P}<0.001)$. The cardinal advantage of cold EMR is perhaps its excellent safety profile, with an extremely low rate of adverse events [39]. Intraprocedural bleeding may occur, usually in the form of minor oozing after resection; however, in most cases it lacks major clinical significance and can be easily managed [40,41]. Although sporadic cases have been reported [42], cold resection also bears zero risk for deep muscular layer injury, perforation or delayed bleeding [40]. Although data remain scarce, cold resection might be valuable for specific patient populations, such as those receiving anticoagulant/antiplatelet medication. 


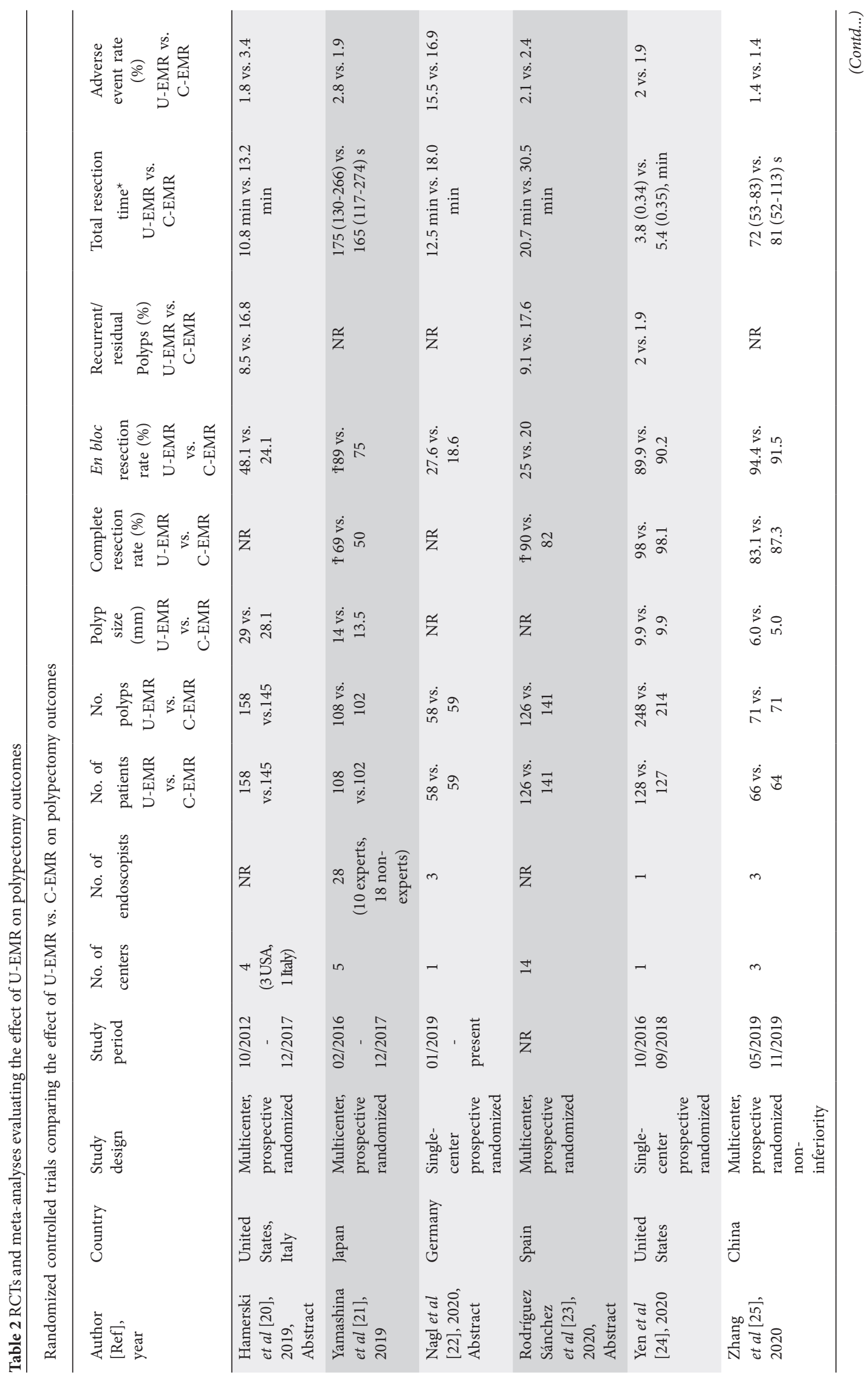




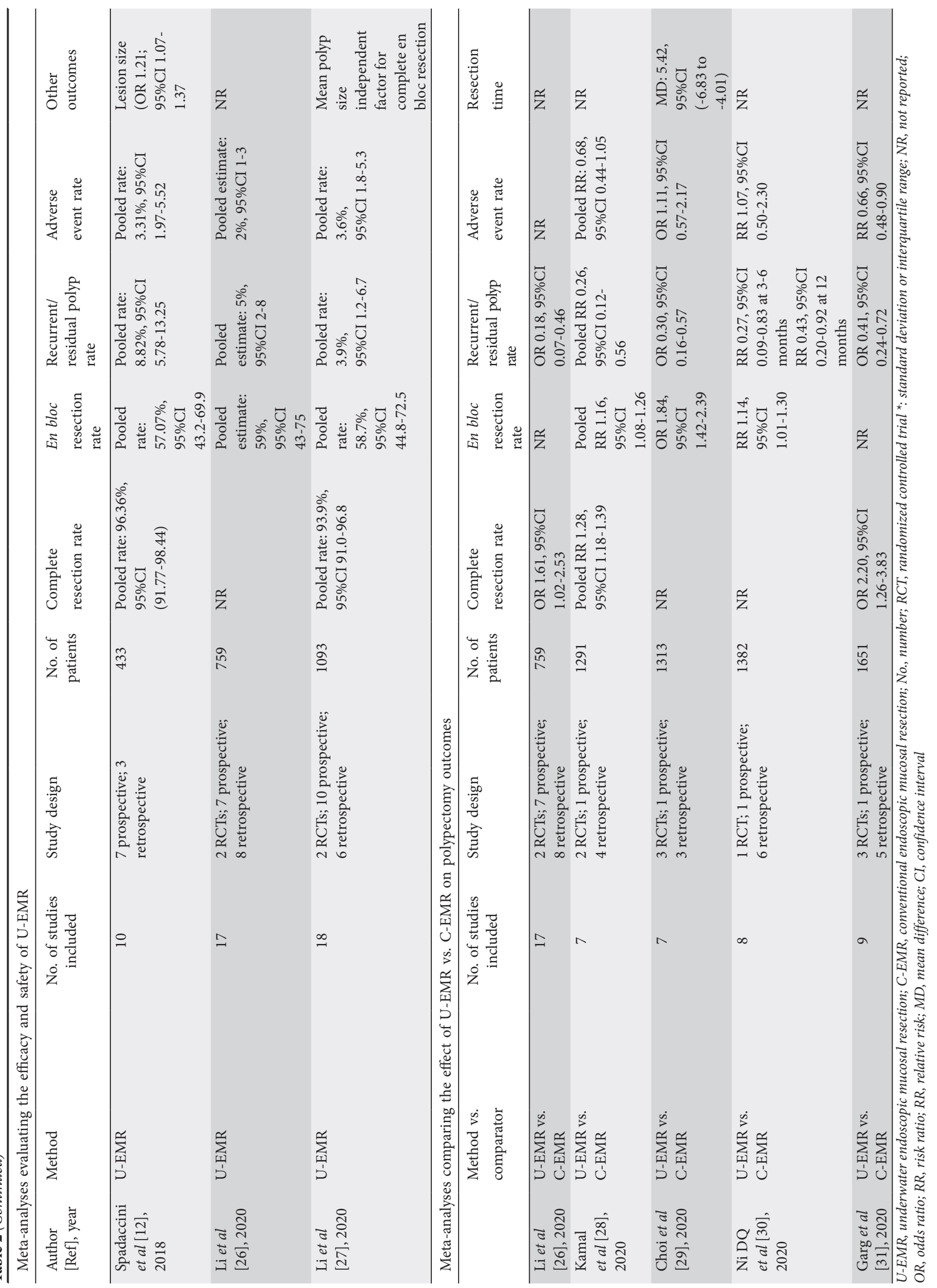




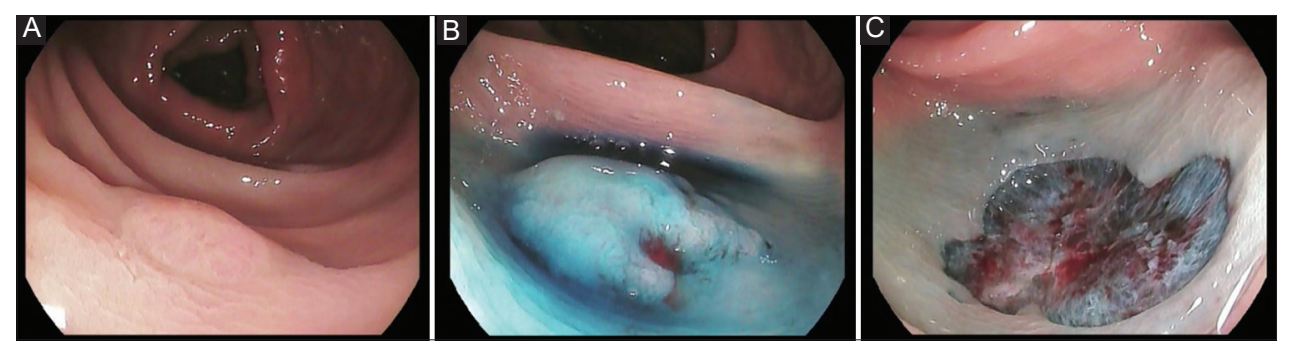

Figure 2 Example of a sessile serrated polyp resected by cold endoscopic mucosal resection (EMR). (A) 10-mm ascending colon sessile serrated polyp with indistinct borders; (B) submucosal injection with normal saline and indigo carmine solution without epinephrine; (C) final cold EMR defect (Photos are from author's personal archive)

\section{Data from meta-analyses}

The efficacy and safety for resecting non-pedunculated colorectal polyps $>10 \mathrm{~mm}$ by cold EMR was the primary focus of a recent systematic review [40] (Table 3). The effect of the resection technique was evaluated via a subgroup analysis. Pooled analysis from 5 studies where cold EMR was performed for resection of polyps $\geq 10 \mathrm{~mm}$, showed a complete resection rate of $99.1 \%$, a residual polyp rate of $4.7 \%$ and an overall adverse event rate of $1.3 \%$ [40]. It should be also highlighted that all the adverse events referred to intraprocedural bleeding or post-polypectomy abdominal pain, while no case of perforation or postprocedural bleeding was recorded.

\section{Cold EMR for sessile serrated polyps (SSPs)}

The efficacy of cold EMR seems to depend on the histological type of the adenoma. The reasons behind this finding remain unknown and speculative, based on the different biological properties of each lesion and the suboptimal polypectomy technique. In an early retrospective study of 30 patients with SSPs of mean size $19 \mathrm{~mm}$, an adenoma recurrence rate of $2.9 \%$ was noted [43]. Contrariwise, no recurrence was observed after resection of large ( $\geq 20 \mathrm{~mm}$ ) SSPs in a prospective observational study [39]. Two retrospective studies focusing exclusively on SSPs reported high complete resection rates along with very low residual or recurrent polyp rates $[44,45]$. In one of the largest studies so far [46], cold EMR outcomes of 566 SSPs $\geq 10 \mathrm{~mm}$, removed from 312 patients, were retrospectively assessed and a residual rate of $8 \%$ (5-12.1\%) was reported. Van Hattem et al also examined cold versus C-EMR for the treatment of large ( $\geq 20 \mathrm{~mm}$ ) SSPs [41], with similar recurrence rates, but cold EMR surpassed the conventional method with respect to safety, since it totally eradicated adverse events (delayed bleeding and perforation). Data from individual studies have been verified in a meta-analysis that evaluated the resection outcomes of SSPs sized $10 \mathrm{~mm}$ or larger [47]. Cold EMR was associated with a significantly lower residual polyp rate $(0.9 \%$ vs. $5 \% ; \mathrm{P}=0.01)$ and less delayed bleeding ( $0 \%$ vs. $2.3 \% ; \mathrm{P}=0.03)$ compared to C-EMR. Taking these observations into account, cold EMR is perhaps the new treatment modality for large SSPs; however, its exact impact on the resection outcomes of conventional adenomas is ambiguous. Data from only 2 studies comparing the residual neoplasia rate from groups of conventional and serrated adenomas are at hand $[38,43]$; their results show higher residual neoplasia rates when cold EMR was applied for adenomas rather than SSPs.

\section{Cap-assisted EMR}

\section{The technique}

The cap is a single-use, transparent plastic device mounted on the distal end of the colonoscope. Beyond its undisputed usefulness in improving colonoscopy outcomes, this addon device facilitates mucosectomy by maintaining sufficient distance between the scope tip and the lesion. During capassisted EMR, the polyp is initially lifted with submucosal fluid injection in a standard manner and the cap is placed against the polyp. The lesion is snared and retracted into the cap using gentle suction until an adequate amount of tissue has been captured; this is followed by total closure of the snare and resection by electrocautery [13]. The main advantage is associated with the optimal visualization of the resection field and suction of adequate normal mucosa. On the other hand, the technique entails a significant risk of perforation, given the potential entrapment of muscularis propria within the cap (Table 1).

\section{The evidence}

There are no randomized trials comparing the cap-assisted technique with C-EMR. The first evidence regarding safety came from a study [48] where analysis of 282 lesions (146 SSPs and 136 lateral spreading tumors) showed a complication rate of $8.6 \%$ and a local recurrence rate of only $4 \%$ (Supplementary Table 1). Favorable conclusions were also reached in a subsequent study [49] that reported eradication and complication rates of $91 \%$ and $10.2 \%$, respectively. Intraprocedural or delayed bleeding occurred more frequently (3.9\% and $2.4 \%$, respectively) but were all successfully treated by endoscopic means, while among the perforation cases $(n=5,3.9 \%)$, only a minority $(n=2)$ finally required surgical treatment. An interesting spin-off is the potential advantage of the cap in facilitating visualization and thus resection of lesions located in difficult colonic sites, e.g., the ileocecal valve (ICV) [50]. Indeed, cap-assisted EMR seems to offer the potential to overcome the objective difficulties 


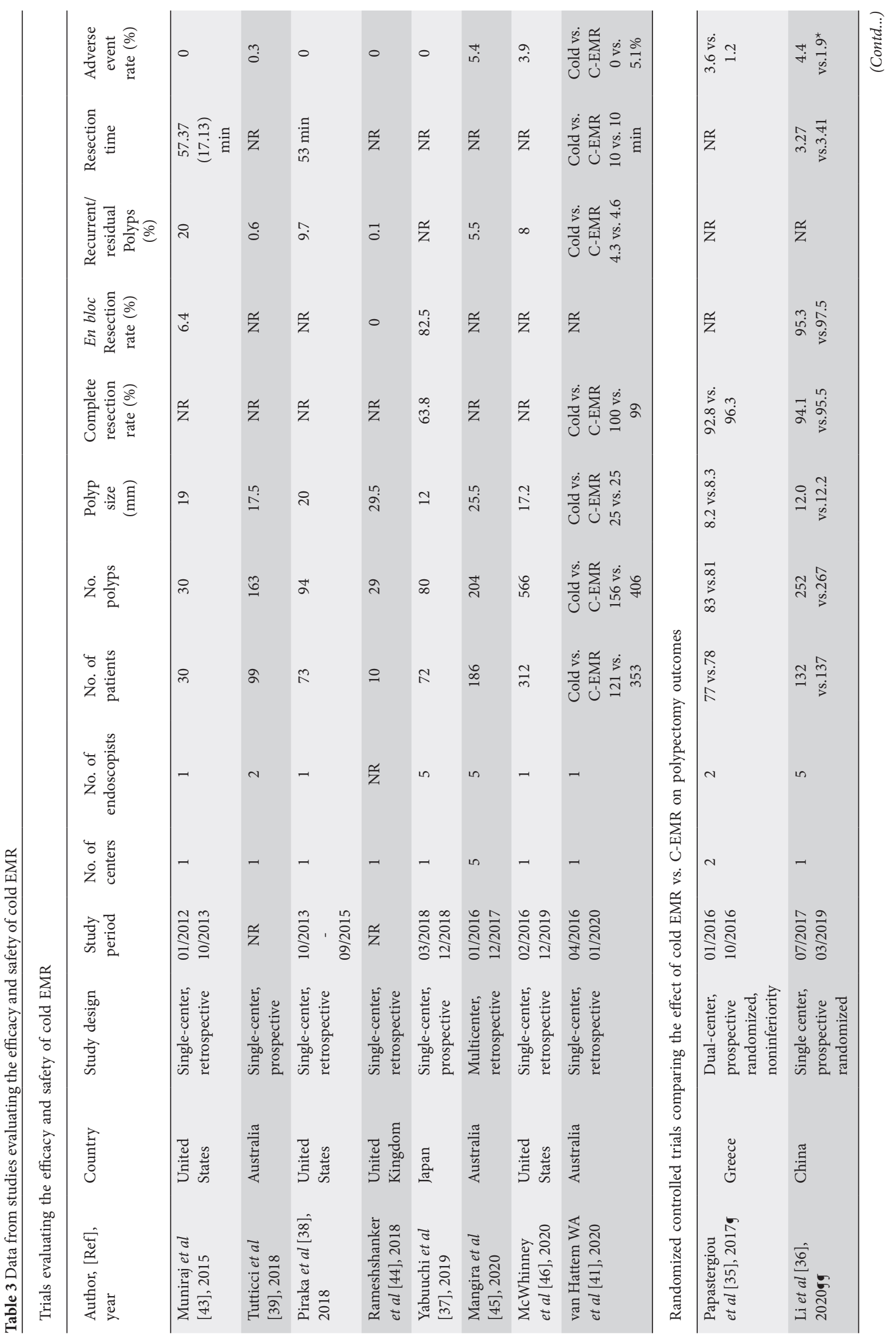




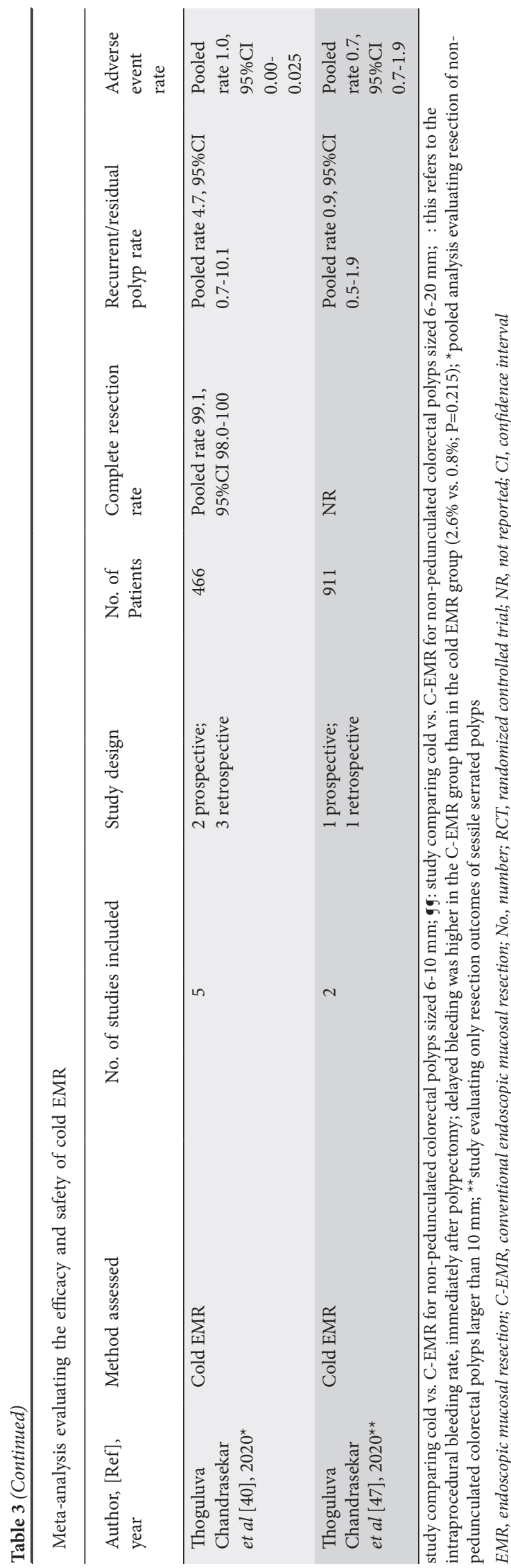

of C-EMR in treating ICV polyps, even in the hands of less experienced endoscopists [51].

\section{Tip-in EMR}

\section{The technique}

Tip-in EMR, or anchored snare-tip EMR, is a simple modification of the conventional EMR procedure. After submucosal injection, a small mucosal incision is made on the oral side of the lesion. Subsequently, the tip of the snare is anchored into the mucosal incision site, allowing the lesion to be grasped entirely, while the tip of the snare remains anchored (Table 1).

\section{The evidence}

Despite its modest appearance, this modification has shown impressive preliminary results (Supplementary Table 1). In a retrospective case-control study, tip-in EMR achieved a significantly higher en bloc resection rate $(\mathrm{n}=39 / 43,90.7 \%$ vs. $\mathrm{n}=58 / 83,69.8 \%)$ and shorter treatment duration (6.64 \pm 0.64 vs. $10.47 \pm 0.81 \mathrm{~min}$ ) compared to C-EMR, for resecting polyps with an average size of $22.9 \mathrm{~mm}$ and $24.3 \mathrm{~mm}$, respectively. Recurrence and perforation rates were also similar between the 2 techniques ( $0 \%$ vs. $7.0 \%$ and $4.6 \%$ vs. $3.6 \%$, respectively) [52]. Promising results were also obtained from a European multicenter study that evaluated the same method, but under the name "anchoring EMR" [53]. The authors managed to achieve a high proportion $(82.8 \%)$ of $\mathrm{R} 0$ resection for lesions $<20 \mathrm{~mm}$ in size, without any perforations. However, the method's efficacy decreased as the size of the lesion increased $(50.0 \%>30 \mathrm{~mm})$. Similarly, en bloc resection rates were reported to be $89.5 \%$ for $15-19 \mathrm{~mm}$ lesions and $76.2 \%$ for 20-25 mm lesions [54]. In another study [55], 46 sessile polyps or laterally spreading tumors with a mean size of $20.4 \mathrm{~mm}$ were removed. En bloc resection was feasible in all cases, while only one patient had local recurrence. Noh and colleagues reported that tip-in EMR is superior to C-EMR in terms of en bloc and complete histologic resection ( $94.7 \%$ vs. $77.0 \%, \mathrm{P}=0.018$, and $76.3 \%$ vs. $54.1 \%, \mathrm{P}=0.022$, respectively) [56].

\section{EMR precutting}

\section{The technique}

This technique is a mixture of C-EMR and endoscopic submucosal dissection (ESD), allowing endoscopists unfamiliar with ESD to resect large polyps en bloc [57]. The solution is injected into the submucosal layer underneath the lesion and a circumferential incision is performed with an ESD knife. Next, a snare is used to capture the lesion at the mucosal circumferential incision site and it is removed by applying the usual polypectomy technique (Table 1). 


\section{The evidence}

In practical terms, this is the hybrid/simplified ESD, or knife-assisted EMR [13]. In an early study, outcomes from 523 non-pedunculated colorectal tumors (499 patients) treated with C-EMR, EMR precutting or ESD were reviewed [58] (Supplementary Table 1). EMR precutting achieved significantly higher en bloc $(65.2 \%$ vs. $42.9 \%, \mathrm{P}<0.001)$ and complete resection $(59.4 \%$ vs. $22.9 \%, \mathrm{P}<0.001)$ rates, and lower recurrence rates $(3.1 \%$ vs. $25.7 \%, \mathrm{P}<0.001)$, compared to C-EMR. Similarly, the method achieved a high en bloc resection rate when evaluated for the resection of large (mean size $25 \mathrm{~mm}$ ) colorectal neoplasms [59]. EMR precutting was compared to ESD, conventional EMR and piecemeal EMR, in terms of complications and local recurrence rates, in another large study assessing colorectal laterally spreading tumors larger than $20 \mathrm{~mm}$ [60]. No cases of recurrence were reported in the EMR precutting group, a rate similar to ESD (0/27, 0\% vs. $0 / 56,0 \%)$ and lower than c-EMR $(1 / 69,1.4 \%)$. A variation of EMR precutting, under the term "knife-assisted snare resection" (KAR) has been evaluated in 2 studies from the same center $[61,62]$. The former [61] showed that the technique can perform well in difficult situations (scarred colonic polyps due to previous EMR attempt). The latter [62], analyzing outcomes from 170 colorectal polyps with a mean size of $46 \mathrm{~mm}$, showed that KAR achieves adequate rates of en bloc resection $(70 / 170,41 \%)$, with low recurrence $(21 / 160,13.1 \%)$ and overall complication (14/170, 8.2\%) rates. EMR precutting was compared to c-EMR in one study [63], where it achieved significantly higher en bloc and histological complete resection rates $(88.6 \%$ vs. $48.5 \%, \mathrm{P}<0.001$, and $71.4 \%$ vs. $42.9 \%, \mathrm{P}=0.02$, respectively, for lesions $\geq 20 \mathrm{~mm}$; $98.0 \%$ vs. $85.7 \%, \mathrm{P}=0.004$, and $87.8 \%$ vs. $67.3 \%, \mathrm{P}<0.001$, respectively, for $<20 \mathrm{~mm}$ ). A subsequent study went a step further, comparing EMR precutting to ESD [64]. EMR precutting was inferior to ESD regarding en bloc (61.5\% vs. $96.6 \%$; $\mathrm{P}=0.001)$ and complete resection rate ( $51.6 \%$ vs. $75.9 \% ; \mathrm{P}=0.009)$, but much safer. These results were replicated in a study that compared the outcomes of endoscopic resection for colorectal laterally spreading tumors [65]. ESD outperformed EMR precutting in terms of en bloc $(87.4 \%$ vs. $51.3 \%, \mathrm{P}<0.001)$ but not complete resection rate $(90.3 \%$ vs. $92.3 \%, \mathrm{P}=0.11)$; notably, the perforation rate was significantly higher for EMR precutting compared to ESD.

\section{Data from meta-analyses}

The efficacy and safety of the technique were evaluated in a recent systematic review and meta-analysis [66]. Analysis from 12 studies, including 720 colorectal lesions from Asian and non-Asian countries, showed that the hybrid technique achieved an overall pooled R0 resection rate of $60.6 \%$ (40.677.5) and an en bloc resection rate of $68.4 \%$ (51.7-81.3), with both outcomes being higher in Asian vs. non-Asian countries. Perhaps the most interesting finding to emerge was that only a single adverse event, out of 655 lesions from 10 studies analyzed, eventually needed surgical intervention, yielding a pooled rate for adverse events needing surgery post-procedure of $1 \%$ (95\%CI $0.4-2.3 \%)$. The standard ESD technique was associated with significantly higher R0 (OR 2.44, 95\%CI 1.23-4.85) and en bloc (OR 6.03, 95\%CI 2.18-16.66) resection rates compared to EMR precutting. However, ESD remains a technically demanding procedure with a slow learning curve, particularly in western countries [67]. In this regard, EMR precutting could be a useful alternative for less experienced endoscopists or those in the first levels of the learning curve.

\section{EMR with band ligation (EMR-L) or endoscopic submucosal resection with ligation (ESMR-L)}

\section{The technique}

The band and snare procedure involves the use of a multi-band ligation device placed at the distal end of the scope. Submucosal injection in this technique is not always necessary and tissue is aspirated into the ligation device, followed by deployment of an elastic band [68]. The tissue is resected below the band using electrical current and clips are placed at the resection site in order to avoid complications. The main advantage is that it allows a deeper resection plane. It has been proven particularly effective for resection of lesions that extend to the submucosal layer, e.g., neuroendocrine tumors (NETs) [69].

\section{The evidence}

The initial evidence supporting the efficacy and safety of this method was published in 2003 [70]. ESMR-L was used for resecting 14 rectal carcinoid tumors (mean size $7.3 \mathrm{~mm}$ ), achieving $100 \%$ therapeutic efficacy compared to conventional polypectomy (histopathologically proven negative margins: $0 / 14,0 \%$ vs. $6 / 14,43 \%, \mathrm{P}<0.05$, respectively), along with a zero complications rate (Supplementary Table 1). Notably, these favorable results were also replicated within larger series of patients that followed [71]. In a dual-center retrospective study, ESMR-L yielded a significantly higher R0 resection compared to C-EMR $(17 / 19,89.5 \%$ vs. $7 / 14,50.0 \%, \mathrm{P}<0.05)$ for removal of rectal carcinoid tumors with size $\leq 10 \mathrm{~mm}$ [72]. Similar conclusions were reached by a prospective, multicenter trial where ESMR-L not only achieved a significantly higher complete resection rate compared to C-EMR (42/45, 93.3\% vs. $36 / 55,65.5 \%, \mathrm{P}=0.001$ ) for same-size tumors, but also an equivalent complication rate $(2 / 45,4.4 \%$ vs. $0 / 55,0.0 \%$, $\mathrm{P}=0.2$ ) [73]. In another study, ESMR-L once again outperformed C-EMR in terms of histologically complete resection (27/29, $93.1 \%$ vs. $82 / 110,74.5 \%, \mathrm{P}=0.03$ ) for rectal neuroendocrine tumors with average size $7 \mathrm{~mm}$, while at the same time the technique also showed valuable results in the long term [74,75]. Preliminary data suggested that the method even achieves at least equal resection outcomes to ESD for rectal carcinoid tumors $<10 \mathrm{~mm}$ in size (complete resection rate $24 / 29,82.8 \%$ vs. $25 / 31,80.6 \% \mathrm{P}=0.83$ ) [76]; however, more recently it was 
shown that ESMR-L may in fact be even more superior to ESD for similar lesions, with respect to therapeutic outcomes and procedure time ( $95.5 \%$ vs.75.0\%, $\mathrm{P}=0.02$ for complete resection rate and $7.1 \pm 4.5$ vs. $24.2 \pm 12.1 \mathrm{~min}, \mathrm{P}<0.001$, for resection time, respectively) [77]. In the largest prospective study comparing the efficacy and safety of the method and ESD for small rectal NETs ( $\leq 10 \mathrm{~mm}$ ) [78], ESMR-L outperformed ESD, achieving a significantly higher pathological complete resection rate (53/53, $100 \%$ vs. $13 / 24,54.2 \%, \mathrm{P}<0.001)$. In one meta-analysis [79], the authors showed that the method achieves a higher complete resection rate than ESD (OR 4.08, 95\%CI 2.42-6.88; $\mathrm{P}<0.001$ ). These data suggest that this method may be considered the firstline option for treating small rectal NETs $(\leq 10 \mathrm{~mm})$.

\section{Critical appraisal and conclusions}

Addition of water prior to mucosectomy is the modification most widely reported in the literature. It has been validated in RCTs and meta-analyses, concerning all aspects of the procedure. Still, one should have in mind that the abovementioned studies were conducted in tertiary referral centers by expert endoscopists; thus, the generalizability of their results is questionable. Cold EMR is the "new kid on the block", as it puts an end to the use of electric current. Its impact on procedure safety is appealing; however, there are still unresolved issues, namely the efficacy when resecting larger conventional adenomas. Tip-in EMR is a promising technique given its simplicity, but further trials are definitely necessary before firm conclusions regarding its effectiveness can be reached. The issue of safety practically restricts the use of cap-assisted EMR to expert hands, while EMR precutting is perhaps valuable only as an intermediate step to achieve competence in ESD. Finally, EMR-L can be a rewarding, handy option, but its efficacy has been tested only for rectal lesions. Despite appearing beneficial in terms of improving EMR outcomes, concerns about the quality of the studies are raised. Most of them were conducted by expert endoscopists across tertiary centers, limiting the generalizability of the results to other real-world clinical practice settings. In addition, the majority were single-center and of retrospective design, enrolling populations with different baseline lesion characteristics and evaluating inconsistent endpoints, or simply aiming to provide results regarding the feasibility of a method rather than comparative evaluations of different approaches. It is imperative for future studies to enroll larger cohorts that will not only broaden the evidence for efficacy, but will enable them to detect changes in clinical and procedural outcomes.

\section{Concluding remarks}

Modifications of the basal technique enhance EMR performance when treating colorectal adenomatous lesions. Each method bears distinct advantages, but also suffers from considerable caveats. Evidence to support their large-scale use may be lacking at this time, but endoscopists should be aware of these techniques and might consider adopting one of these innovative treatment modalities on a case-by-case basis.

\section{References}

1. Zauber AG, Winawer SJ, O'Brien MJ, et al. Colonoscopic polypectomy and long-term prevention of colorectal-cancer deaths. N Engl J Med 2012;366:687-696.

2. Rex DK. Narrow-band imaging without optical magnification for histologic analysis of colorectal polyps. Gastroenterology 2009;136:1174-1181.

3. Gallegos-Orozco JF, Gurudu SR. Complex colon polypectomy. Gastroenterol Hepatol (N Y) 2010;6:375-382.

4. Ferlitsch M, Moss A, Hassan C, et al. Colorectal polypectomy and endoscopic mucosal resection (EMR): European Society of Gastrointestinal Endoscopy (ESGE) Clinical Guideline. Endoscopy 2017;49:270-297.

5. Kandel P, Wallace MB. Colorectal endoscopic mucosal resection (EMR). Best Pract Res Clin Gastroenterol 2017;31:455-471.

6. Hurlstone DP, Sanders DS, Cross SS, et al. Colonoscopic resection of lateral spreading tumours: a prospective analysis of endoscopic mucosal resection. Gut 2004;53:1334-1339.

7. Belderbos TD, Leenders M, Moons LM, Siersema PD. Local recurrence after endoscopic mucosal resection of nonpedunculated colorectal lesions: systematic review and meta-analysis. Endoscopy 2014;46:388-402.

8. Komeda Y, Watanabe T, Sakurai T, et al. Risk factors for local recurrence and appropriate surveillance interval after endoscopic resection. World J Gastroenterol 2019;25:1502-1512.

9. Binmoeller KF. Underwater EMR without submucosal injection: is less more? Gastrointest Endosc 2019;89:1117-1119.

10. Ngamruengphong S, Pohl H, Haito-Chavez Y, Khashab MA. Update on difficult polypectomy techniques. Curr Gastroenterol Rep 2016;18:3.

11. Barclay RL, Percy DB. Underwater endoscopic mucosal resection without submucosal injection (UEMR) for large colorectal polyps: a community-based series. Am J Surg 2020;220:693-696.

12. Spadaccini M, Fuccio L, Lamonaca L, et al. Underwater EMR for colorectal lesions: a systematic review with meta-analysis (with video). Gastrointest Endosc 2019;89:1109-1116.

13. Gaglia A, Sarkar S. Evaluation and long-term outcomes of the different modalities used in colonic endoscopic mucosal resection. Ann Gastroenterol 2017;30:145-151.

14. Nett A, Binmoeller K. Underwater endoscopic mucosal resection. Gastrointest Endosc Clin N Am 2019;29:659-673.

15. Binmoeller KF, Weilert F, Shah J, Bhat Y, Kane S. "Underwater" EMR without submucosal injection for large sessile colorectal polyps (with video). Gastrointest Endosc 2012;75:1086-1091.

16. Uedo N, Nemeth A, Johansson GW, Toth E, Thorlacius H. Underwater endoscopic mucosal resection of large colorectal lesions. Endoscopy 2015;47:172-174.

17. Schenck RJ, Jahann DA, Patrie JT, et al. Underwater endoscopic mucosal resection is associated with fewer recurrences and earlier curative resections compared to conventional endoscopic mucosal resection for large colorectal polyps. Surg Endosc 2017;31:4174-4183.

18. Chien HC, Uedo N, Hsieh PH. Comparison of underwater and conventional endoscopic mucosal resection for removing sessile colorectal polyps: a propensity-score matched cohort study. Endosc Int Open 2019;7:E1528-E1536.

19. Curcio G, Granata A, Ligresti D, et al. Underwater colorectal EMR: remodeling endoscopic mucosal resection. Gastrointest Endosc 2015;81:1238-1242.

20. Hamerski C, Samarasena J, Lee DP, et al. Underwater versus 
conventional endoscopic mucosal resection for the treatment of colorectal laterally spreading tumors: results from an international, multicenter, randomized controlled trial. Am J Gastroenterol 2019;114(Suupl 75):125.

21. Yamashina T, Uedo N, Akasaka T, et al. Comparison of underwater vs conventional endoscopic mucosal resection of intermediate-Size colorectal polyps. Gastroenterology 2019;157:451-461.

22. Nagl S, Ebigbo A, Braun G, et al. Underwater-versus conventional endoscopic mucosal resection of large sessile or flat colonic polyps: preliminary results of a prospective randomized controlled trial. Endoscopy 2020;52(Suppl 1):S6

23. Rodríguez Sánchez J, Coto Ugarte D, Koeklin HIU, et al. Efficacy of underwater endoscopic mucosal resection for the treatment of large complex colorectal lesions: a randomized and multicenter control trial. Endoscopy 2020;52(Suppl 01):S111.

24. Yen AW, Leung JW, Wilson MD, Leung FW. Underwater versus conventional endoscopic resection of nondiminutive nonpedunculated colorectal lesions: a prospective randomized controlled trial (with video). Gastrointest Endosc 2020;91:643-654.

25. Zhang Z, Xia Y, Cui $\mathrm{H}$, et al. Underwater versus conventional endoscopic mucosal resection for small size non-pedunculated colorectal polyps: a randomized controlled trial: (UEMR vs. CEMR for small size non-pedunculated colorectal polyps). $B M C$ Gastroenterol 2020;20:311.

26. Li P, Ma B, Gong S, Zhang X, Li W. Underwater endoscopic mucosal resection for colorectal lesions: a meta-analysis. Surg Endosc 2021;35:3003-3013.

27. Li DF, Lai MG, Yang MF, et al. The efficacy and safety of underwater endoscopic mucosal resection for $\geq 10$ - $\mathrm{mm}$ colorectal polyps: systematic review and meta-analysis. Endoscopy 2021;53:636-646.

28. Kamal F, Khan MA, Lee-Smith W, et al. Underwater vs conventional endoscopic mucosal resection in the management of colorectal polyps: a systematic review and meta-analysis. Endosc Int Open 2020;8:E1264-E1272.

29. Choi AY, Moosvi Z, Shah S, et al. Underwater versus conventional EMR for colorectal polyps: systematic review and meta-analysis. Gastrointest Endosc 2021;93:378-389.

30. Ni DQ, Lu YP, Liu XQ, Gao LY, Huang X. Underwater vs conventional endoscopic mucosal resection in treatment of colorectal polyps: a meta-analysis. World J Clin Cases 2020;8:4826-4837.

31. Garg R, Singh A, Mohan BP, Mankaney G, Regueiro M, Chahal P. Underwater versus conventional endoscopic mucosal resection for colorectal lesions: a systematic review and meta-analysis. Endosc Int Open 2020;8:E1884-E1894.

32. Tutticci NJ, Kheir AO, Hewett DG. The cold revolution: how far can it go? Gastrointest Endosc Clin N Am 2019;29:721-736.

33. Horiuchi A, Hosoi K, Kajiyama M, Tanaka N, Sano K, Graham DY. Prospective, randomized comparison of 2 methods of cold snare polypectomy for small colorectal polyps. Gastrointest Endosc 2015;82:686-692.

34. Anderloni A, Jovani M, Hassan C, Repici A. Advances, problems, and complications of polypectomy. Clin Exp Gastroenterol 2014;7:285-296.

35. Papastergiou V, Paraskeva KD, Fragaki M, et al. Cold versus hot endoscopic mucosal resection for nonpedunculated colorectal polyps sized 6-10 mm: a randomized trial. Endoscopy 2018;50:403-411.

36. Li D, Wang W, Xie J, et al. Efficacy and safety of three different endoscopic methods in treatment of 6-20 mm colorectal polyps. Scand J Gastroenterol 2020;55:362-370.

37. Yabuuchi Y, Imai K, Hotta K, et al. Efficacy and safety of coldsnare endoscopic mucosal resection for colorectal adenomas 10 to $14 \mathrm{~mm}$ in size: a prospective observational study. Gastrointest Endosc 2020;92:1239-1246.

38. Piraka C, Saeed A, Waljee AK, Pillai A, Stidham R, Elmunzer BJ. Cold snare polypectomy for non-pedunculated colon polyps greater than 1cm. Endosc Int Open 2017;5:E184-E189.

39. Tutticci NJ, Hewett DG. Cold EMR of large sessile serrated polyps at colonoscopy (with video). Gastrointest Endosc 2018;87:837-842.

40. Thoguluva Chandrasekar V, Spadaccini M, Aziz M, et al. Cold snare endoscopic resection of nonpedunculated colorectal polyps larger than $10 \mathrm{~mm}$ : a systematic review and pooled-analysis. Gastrointest Endosc 2019;89:929-936.

41. van Hattem WA, Shahidi N, Vosko S, et al. Piecemeal cold snare polypectomy versus conventional endoscopic mucosal resection for large sessile serrated lesions: a retrospective comparison across two successive periods. Gut 2020 Nov 10 [Online ahead of print]. doi: 10.1136/gutjnl-2020-321753

42. Nogales Rincón, García García J, Ortega Lobete O, et al. The "double string" sign: a warning image after cold endoscopic mucosal resection. Endoscopy 2021;53:E71-E72.

43. Muniraj T, Sahakian A, Ciarleglio MM, Deng Y, Aslanian HR. Cold snare polypectomy for large sessile colonic polyps: a single-center experience. Gastroenterol Res Pract 2015;2015:175959.

44. Rameshshanker R, Tsiamoulos Z, Latchford A, Moorghen M, Saunders BP. Resection of large sessile serrated polyps by cold piecemeal endoscopic mucosal resection: Serrated COld Piecemeal Endoscopic mucosal resection (SCOPE). Endoscopy 2018;50:E165-E167.

45. Mangira D, Cameron K, Simons K, et al. Cold snare piecemeal EMR of large sessile colonic polyps $\geq 20 \mathrm{~mm}$ (with video). Gastrointest Endosc 2020;91:1343-1352.

46. McWhinney CD, Vemulapalli KC, El Rahyel A, Abdullah N, Rex DK. Adverse events and residual lesion rate after cold endoscopic mucosal resection of serrated lesions $\geq 10 \mathrm{~mm}$. Gastrointest Endosc 2021;93:654-659.

47. Thoguluva Chandrasekar V, Aziz M, Patel HK, et al. Efficacy and safety of endoscopic resection of sessile serrated polyps $10 \mathrm{~mm}$ or larger: a systematic review and meta-analysis. Clin Gastroenterol Hepatol 2020;18:2448-2455.

48. Conio M, Blanchi S, Repici A, Ruggeri C, Fisher DA, Filiberti R. Cap-assisted endoscopic mucosal resection for colorectal polyps. Dis Colon Rectum 2010;53:919-927.

49. Kashani A, Lo SK, Jamil LH. Cap-assisted endoscopic mucosal resection is highly effective for nonpedunculated colorectal lesions. J Clin Gastroenterol 2016;50:163-168.

50. Conio M, Blanchi S, Filiberti R, Ruggeri C, Fisher DA. Capassisted endoscopic mucosal resection of large polyps involving the ileocecal valve. Endoscopy 2010;42:677-680.

51. Lew D, Kashani A, Lo SK, Jamil LH. Efficacy and safety of capassisted endoscopic mucosal resection of ileocecal valve polyps. Endosc Int Open 2020;8:E241-E246.

52. Sato Y, Ozawa SI, Yasuda H, et al. Tip-in endoscopic mucosal resection for large colorectal sessile polyps. Surg Endosc 2021;35:1820-1826.

53. Pioche M, Wallenhorst $\mathrm{T}$, Lepetit $\mathrm{H}$, et al. Endoscopic mucosal resection with anchoring of the snare tip: multicenter retrospective evaluation of effectiveness and safety. Endosc Int Open 2019;7:E1496-E1502.

54. Imai K, Hotta K, Ono H. Tip-in endoscopic mucosal resection: Simple, efficacious trick for endoscopic mucosal resections of large colorectal polyps. Dig Endosc 2021;33:203.

55. Lee C-Y, Chen M-Y, Lin H-J, Chien H-Y. Safety and efficacy of tipin endoscopic mucosal resection for large sessile colorectal polyps: A single-center experience in Taiwan. Adv Dig Med 2020;7:58-62.

56. Noh SM, Kim JY, Park JC, et al. Tip-in versus conventional endoscopic mucosal resection for flat colorectal neoplasia $10 \mathrm{~mm}$ or larger in size. Int J Colorectal Dis 2020;35:1283-1290.

57. Tanaka S, Kashida H, Saito Y, et al. Japan Gastroenterological Endoscopy Society guidelines for colorectal endoscopic submucosal dissection/endoscopic mucosal resection. Dig Endosc 
2020;32:219-239.

58. Lee EJ, Lee JB, Lee SH, Youk EG. Endoscopic treatment of large colorectal tumors: comparison of endoscopic mucosal resection, endoscopic mucosal resection-precutting, and endoscopic submucosal dissection. Surg Endosc 2012;26:2220-2230.

59. Sakamoto T, Matsuda T, Nakajima T, Saito Y. Efficacy of endoscopic mucosal resection with circumferential incision for patients with large colorectal tumors. Clin Gastroenterol Hepatol 2012;10:22-26.

60. Terasaki M, Tanaka S, Oka S, et al. Clinical outcomes of endoscopic submucosal dissection and endoscopic mucosal resection for laterally spreading tumors larger than $20 \mathrm{~mm}$. $J$ Gastroenterol Hepatol 2012;27:734-740.

61. Chedgy FJ, Bhattacharyya R, Kandiah K, Longcroft-Wheaton G, Bhandari P. Knife-assisted snare resection: a novel technique for resection of scarred polyps in the colon. Endoscopy 2016;48:277-280.

62. Bhattacharyya R, Chedgy FJ, Kandiah K, Longcroft-Wheaton G, Bhandari P. Knife-assisted snare resection (KAR) of large and refractory colonic polyps at a Western centre: Feasibility, safety and efficacy study to guide future practice. United European Gastroenterol J 2016;4:466-473.

63. Yoshida N, Inoue K, Dohi O, et al. Efficacy of precutting endoscopic mucosal resection with full or partial circumferential incision using a snare tip for difficult colorectal lesions. Endoscopy 2019;51:871-876.

64. Kim YJ, Kim ES, Cho KB, et al. Comparison of clinical outcomes among different endoscopic resection methods for treating colorectal neoplasia. Dig Dis Sci 2013;58:1727-1736.

65. Jung JS, Hong JY, Oh HH, et al. Clinical outcomes of endoscopic resection for colorectal laterally spreading tumors with advanced histology. Surg Endosc 2019;33:2562-2571.

66. Fuccio L, Hassan C, Ponchon T, et al. Clinical outcomes after endoscopic submucosal dissection for colorectal neoplasia: a systematic review and meta-analysis. Gastrointest Endosc 2017;86:74-86.

67. Probst A, Golger D, Anthuber M, Märkl B, Messmann H. Endoscopic submucosal dissection in large sessile lesions of the rectosigmoid: learning curve in a European center. Endoscopy 2012;44:660-667.

68. Kantsevoy SV, Adler DG, Conway JD, et al; ASGE Technology Committee. Endoscopic mucosal resection and endoscopic submucosal dissection. Gastrointest Endosc 2008;68:11-18.

69. Bertani E, Ravizza D, Milione M, et al. Neuroendocrine neoplasms of rectum: a management update. Cancer Treat Rev 2018;66:45-55.

70. Ono A, Fujii T, Saito Y, et al. Endoscopic submucosal resection of rectal carcinoid tumors with a ligation device. Gastrointest Endosc 2003;57:583-587.

71. Mashimo Y, Matsuda T, Uraoka T, et al. Endoscopic submucosal resection with a ligation device is an effective and safe treatment for carcinoid tumors in the lower rectum. J Gastroenterol Hepatol 2008;23:218-221.

72. Ebi M, Nakagawa S, Yamaguchi Y, et al. Endoscopic submucosal resection with an endoscopic variceal ligation device for the treatment of rectal neuroendocrine tumors. Int J Colorectal Dis 2018;33:1703-1708.

73. Kim HH, Park SJ, Lee SH, et al. Efficacy of endoscopic submucosal resection with a ligation device for removing small rectal carcinoid tumor compared with endoscopic mucosal resection: analysis of 100 cases. Dig Endosc 2012;24:159-163.

74. Lee HS, Moon HS, Kwon IS, et al. Comparison of conventional and modified endoscopic mucosal resection methods for the treatment of rectal neuroendocrine tumors. Surg Endosc 2020 Oct 22 [Online ahead of print]. doi: 10.1007/s00464-020-08097-Z

75. Takita M, Sakai E, Nakao T, et al. Clinical outcomes of patients with small rectal neuroendocrine tumors treated using endoscopic submucosal resection with a ligation device. Digestion 2019;99:72-78.

76. Choi CW, Kang DH, Kim HW, et al. Comparison of endoscopic resection therapies for rectal carcinoid tumor: endoscopic submucosal dissection versus endoscopic mucosal resection using band ligation. J Clin Gastroenterol 2013;47:432-436.

77. Lim HK, Lee SJ, Baek DH, et al. Resectability of rectal neuroendocrine tumors using endoscopic mucosal resection with a ligation band device and endoscopic submucosal dissection. Gastroenterol Res Pract 2019;2019:8425157.

78. Bang BW, Park JS, Kim HK, Shin YW, Kwon KS, Kim JM. Endoscopic resection for small rectal neuroendocrine tumors: comparison of endoscopic submucosal resection with band ligation and endoscopic submucosal dissection. Gastroenterol Res Pract 2016;2016:6198927.

79. Pan J, Zhang X, Shi Y, Pei Q. Endoscopic mucosal resection with suction vs. endoscopic submucosal dissection for small rectal neuroendocrine tumors: a meta-analysis. Scand J Gastroenterol 2018;53:1139-1145. 
Supplementary material

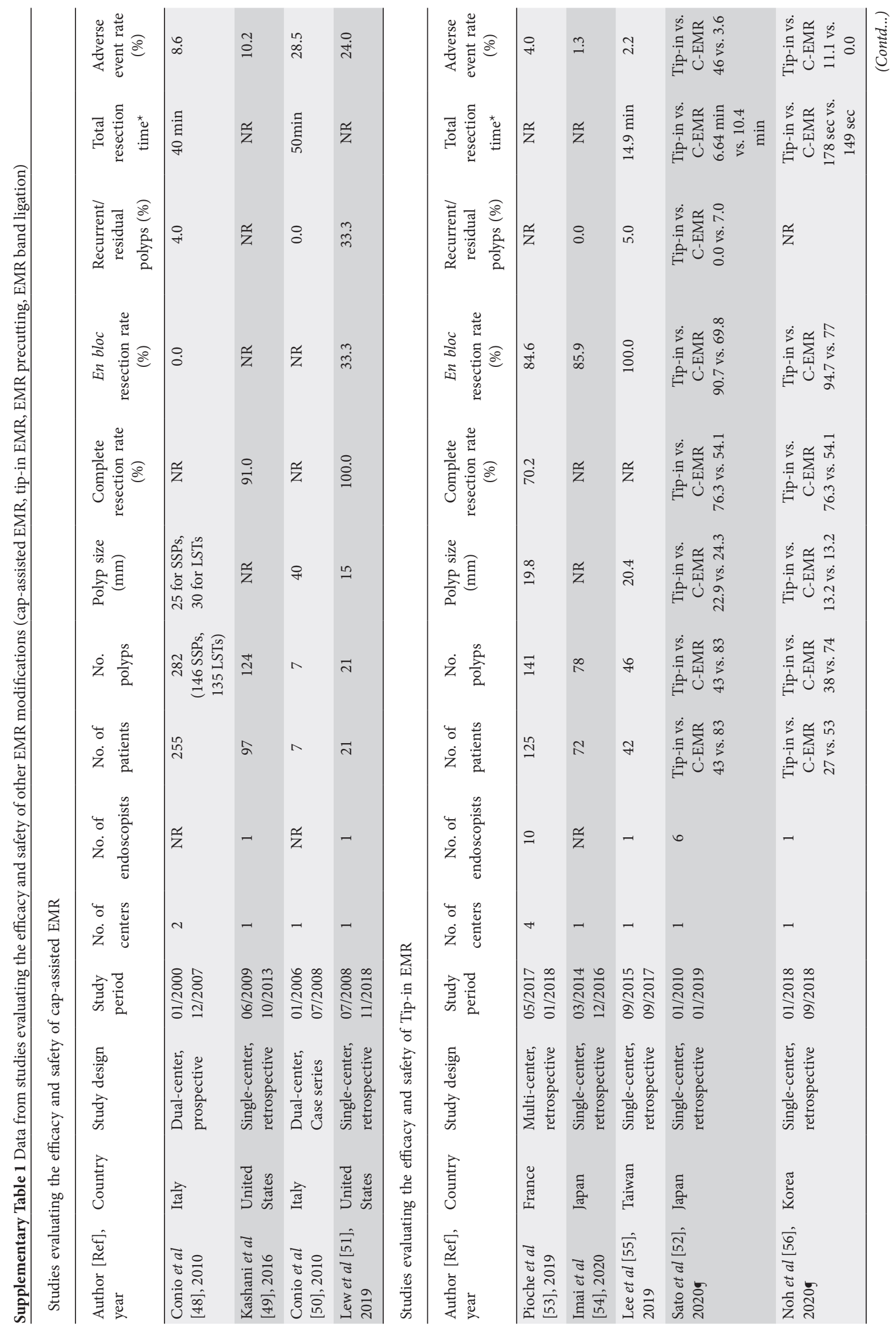




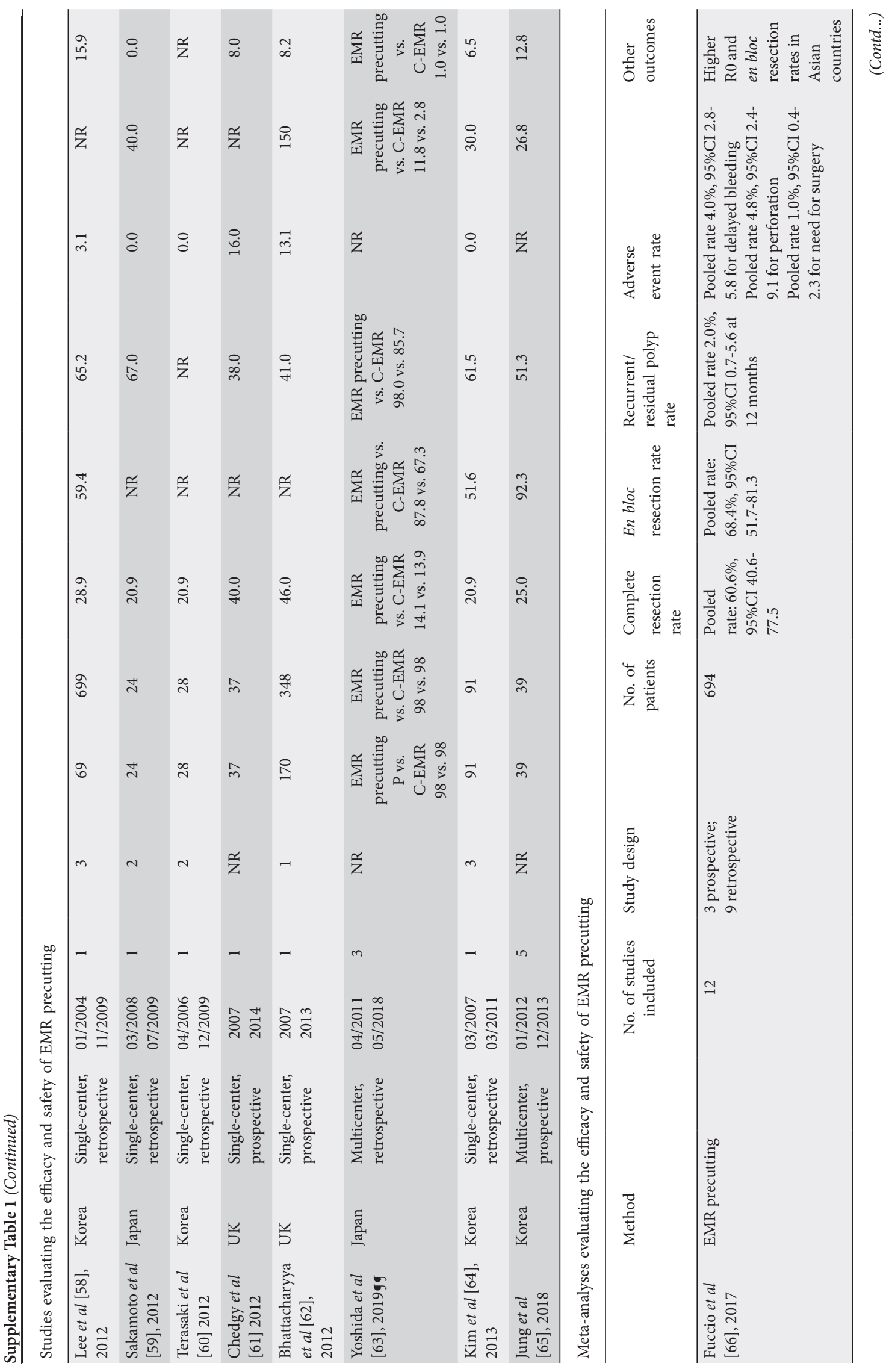




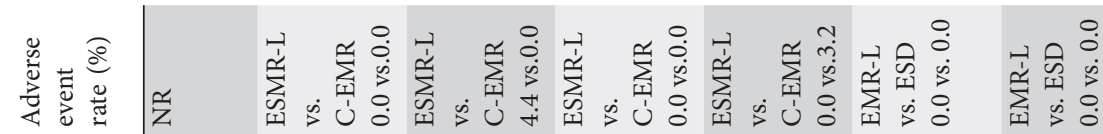

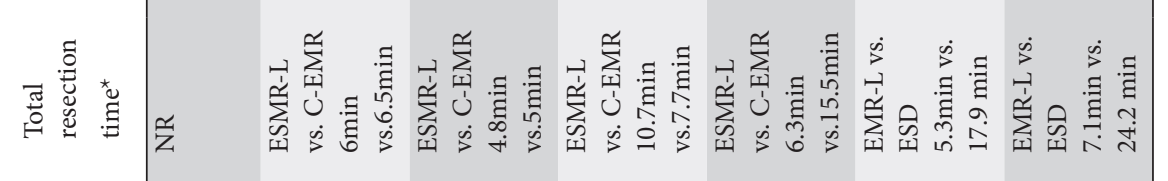

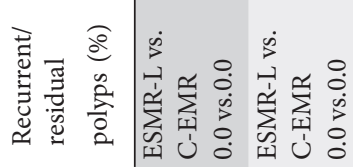

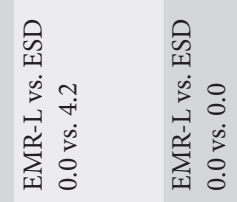

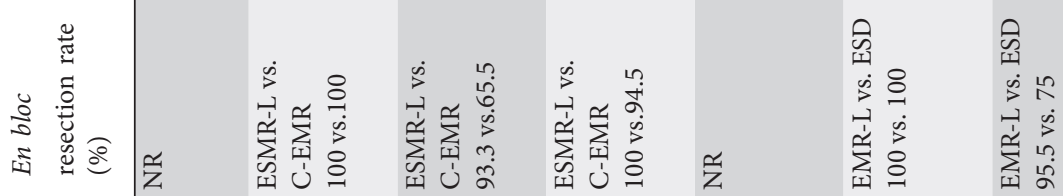

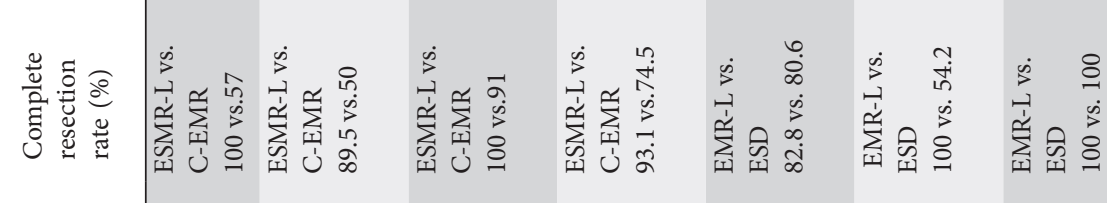

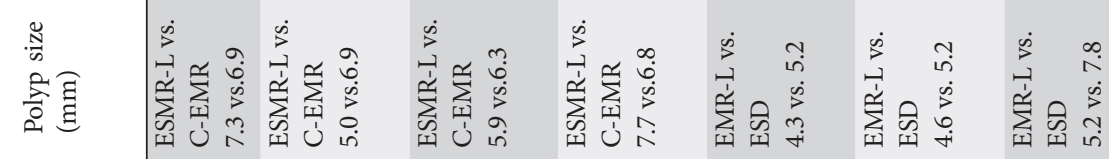

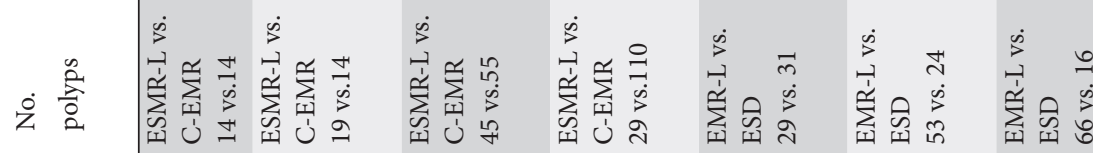
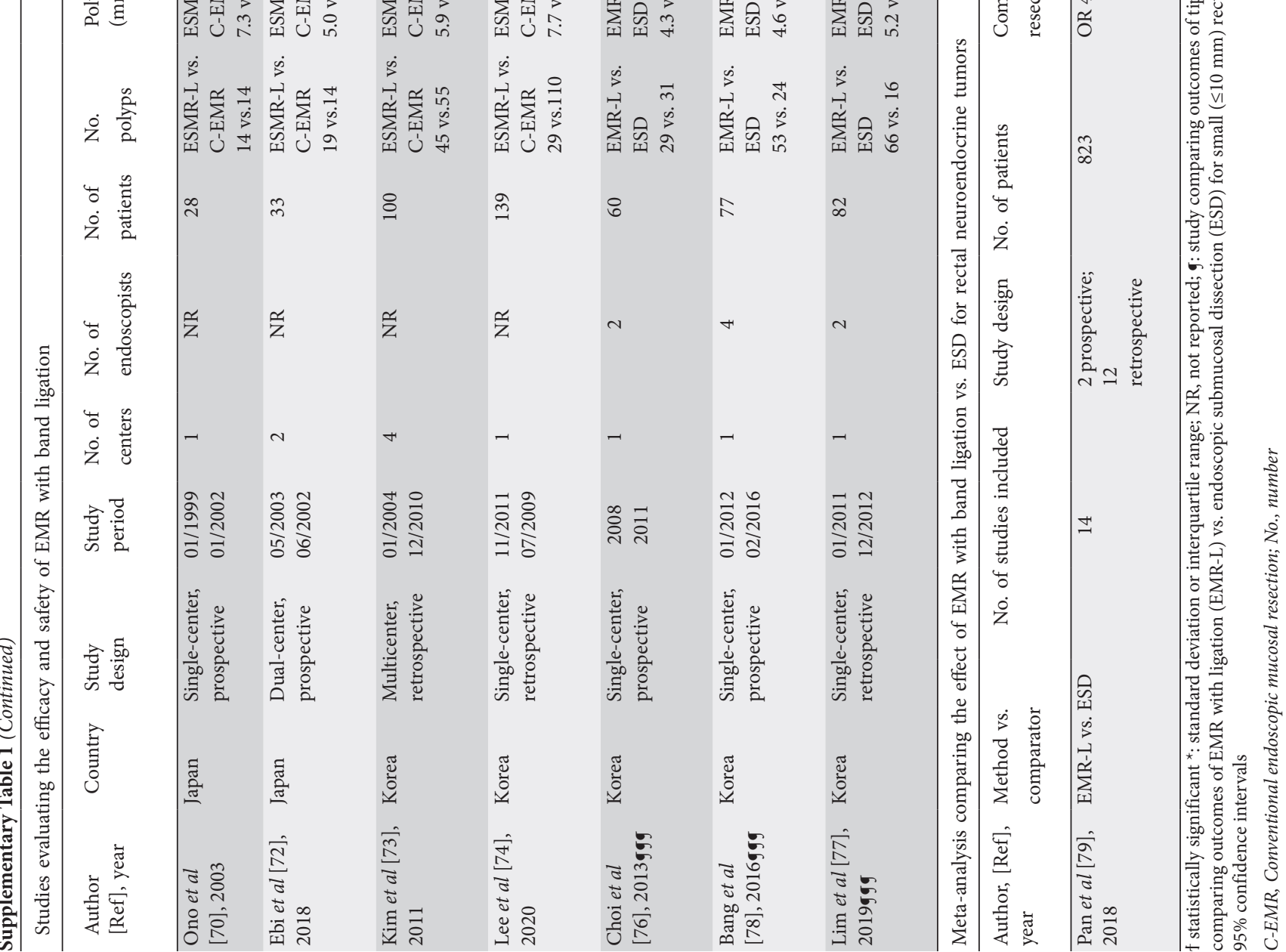